Zu1F

Zeitschrift für wirtschaftliche Fertigung

Herausgeber:

Professor Dr.-Ing. Günter Spur

Techn. Universität

Fasanenstr. 90

1000 Berlin 12

Tel.: 030/3143349

\section{Schriftleitung:}

Dipl.-Ing. Rudi Jonck

Sonnenbühl 18 B

7000 Stuttgart 70

Tel.: $0711 / 766303$

\section{Dipl.-Ing. Hans Rittinghausen}

Techn. Universität

Fasanenstr. 90

1000 Berlin 12

Tel.: 030/3144962

Manuskripte sowie Mitteilungen, die den redaktionellen Inhalt betreffen, sind an den Herausgeber der Zeitschrift Prof. Dr-Ing. Günter Spur, Technische Universität Berlin, Fasanenstraße 90, 1000 Berlin 12, zu senden.

\section{Organschaft:}

AWT-Arbeitsgemeinschaft

Wärmebehandlung und WerkstoffTechnik e.V.

Vorsitzender:

Prof. Dr.-Ing. C. Razim

i. Hs. Daimler-Benz AG

Postfach 202

7000 Stuttgart 60

Tel.: 0711/3022182

\section{Carl Hanser Verlag}

Kolbergerstr. 22, D-8000 München 80, Postanschrift:

Postfach 860420,8000 München 86

Tel.-Sa.-Nr. (089) 985861, Telex 05-22837

c) Copyright by Carl Hanser Verlag
74. Jahrgang, Juni 1979 , Seite $261-332$

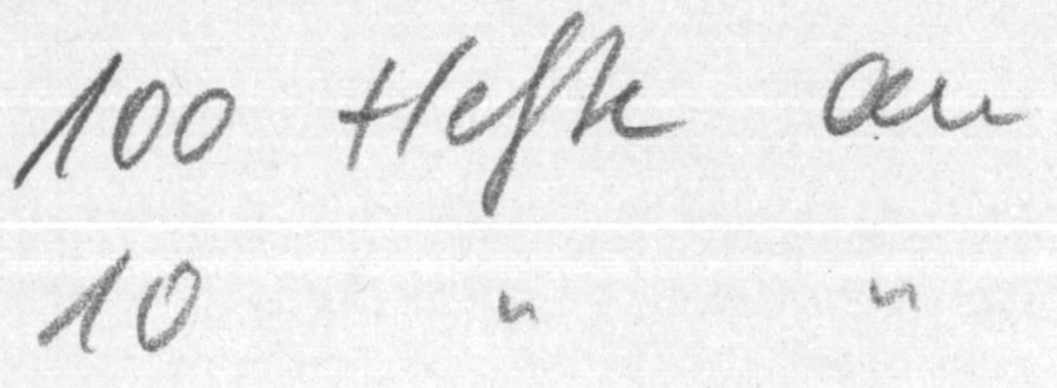

G. Spur, Produktionstechnik im Wandel . . . . . . . . . . . . . . . 261 Festbeitrag aus Anlaß des 75jährigen Bestehens des Instituts für Werkzeugmaschinen und Fertigung der Technischen Universtiät Berlin

\title{
Neue Produktionsstrukturen
}

C. Kessler, Wandel der Fertigungstechnik in der elektrotechnischen Industrie 273

\section{Arbeitswissenschaft}

H.-J. Warnecke und H.-J. Bullinger, Arbeitswissenschaftliche Aspekte neuer Produktionsstrukturen

\section{Automatisierter Materialfluß}

J. F. Engelberger, Neue Entwicklungen der Handhabungs- und Montagetechnik in den USA . . . . . . . . . . . . . . . . . . . . . . . . . . 291

\section{Produktionstechnologie}

G. Hartwich, Neuzeitliche Produktionsanlagen in der Automobilindustrie . . . 301 Einspindeliger Drehautomat mit CNC-Steuerung . . . . . . . . . . . . . . 309 H. Hucks, Fertigungstechnik im Wandel als Folge von Substitutionsprozessen 310 Rechnerunterstütze Zeichnungserstellung und Arbeitsplanung . . . . . . 318

\section{Rechnergesteuerte Produktionsmittel}

W. Panknin, Rechnergesteuerte Fertigungssysteme in der Blechbearbeitung . 319 CNC-Drehmaschine mit automatischer Zubringeeinrichtung . . . . . . . 325

\section{Qualitätssicherung}

M. Röhle, Integrierte Qualitätssicherung für die Fertigung elektronischer Bauelemente . . . . . . . . . . . . . . . . . 326

Übersicht über weitere Beiträge zum PTK'79 . . . . . . . . . . . . . . 332

\section{Zur Titelanzeige}

\section{In knapp drei Jahren fertigt GILDEMEISTER}

über 1000 N.E.F.-Maschinen

Man schreibt das Jahr 1976, als GILDEMEISTER als erster Hersteller eine Microprocessor-Steuerung in eine UniversalDrehmaschine integriert. Die N.E.F. ist geboren. Maßgebend für den Erfolg sind nicht nur die kostengünstigen elektronischen Bauelemente, sondern die bedienungsgerechte Anordnung der Steuerung, die serienmäßig eingebauten Programmroutinen und die für

jeden Dreher verständliche Dateneingabe. Eine normalerweise übliche Organisation für Numerikmaschinen ist nicht erforderlich. Eine wichtige Forderung „Humanisierung des Arbeitsplatzes" wird mit der N.E.F. erfüllt: Der Bedienungsmann ist weitgehend von körperlicher Anstrengung entlastet, er konzentriert sich auf Programmeingabe und die gestellte Aufgabe.

Das Titelbild soll dieses unterstreichen.

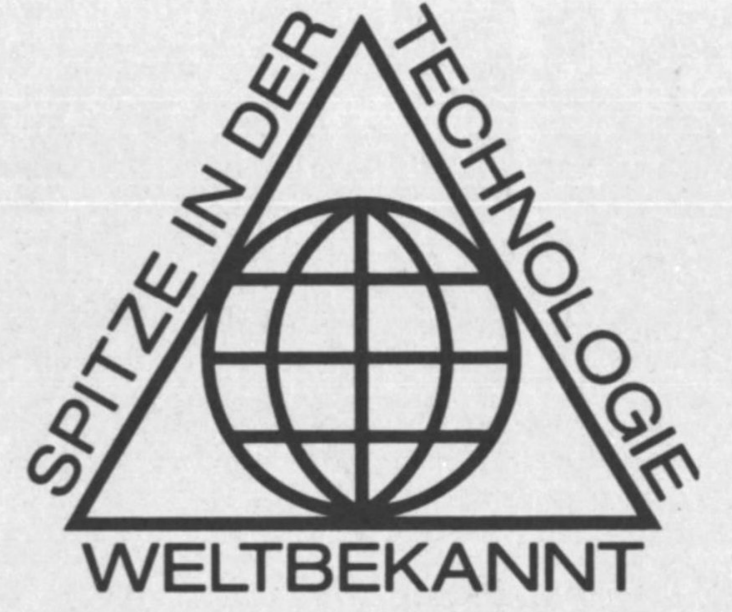

GILDEMEISTER Aktiengesellschaft Am Hauptbahnhhof, D-4800 Bielefeld 1
GILDEMEISTER 